\begin{tabular}{|l|l|}
\hline Postprint Version & 1.0 \\
\hline Journal website & $\underline{\text { http://www.springerlink.com/content/u622284777020376/ }}$ \\
\hline Pubmed link & $\underline{\text { http://www.ncbi.nlm.nih.org/pubmed/19370351 }}$ \\
\hline DOI & $10.1007 / \mathrm{s} 00296-009-0926-3$ \\
\hline
\end{tabular}

This is a NIVEL certified Post Print, more info at http://www.nivel.eu

\title{
Measuring patients' experiences with rheumatic care: the consumer quality index rheumatoid arthritis.
}

\author{
MARLOES ZUIDGEEST ${ }^{1}$, HERMAN SIXMA ${ }^{1}$ AND JANY RADEMAKERS ${ }^{1}$ \\ NIVEL, Netherlands Institute for Health Services Research, P.O. Box 1568, 3500 \\ BN Utrecht, The Netherlands \\ Marloes Zuidgeest Email: m.zuidgeest@nivel.nl
}

\begin{abstract}
Rheumatologists and other caregivers can learn from patients' experiences with the quality of care that can be measured with the CQ-index Rheumatoid Arthritis (CQ-index RA) survey. Patients with RA $(n=590)$ received this survey were they rated their actual experiences and what they find important in rheumatic healthcare. Descriptive analyses and psychometric methods were used to test the reliability. The response rate was $69 \%$. The items in the pilot instrument could be grouped into 10 scales ( $\alpha$ ranged from 0.77 to 0.94 ). The most important quality aspects according to patients concerned the alertness when prescribing medication. Providing patients with information on a special website of the hospital about RA was the highest quality improvement aspect. The results of this study show that the CQ-index RA is a reliable instrument for quality assessment from the patients' perspective. The instrument provides rheumatologists and other caregivers with feedback for service improvement initiatives.
\end{abstract}

\section{INTRODUCTION}

Quality of care has become increasingly important in the evaluation of healthcare and healthcare services $\left[{ }^{1}{ }^{3}\right]$. Evaluating rheumatic healthcare quality is a major issue given to the care need profile of patients with rheumatoid arthritis (RA) and their long-term dependency on healthcare $\left[{ }^{4}\right]$. Evaluation of quality of care is often performed by healthcare professionals. However, patients' perspectives on healthcare quality differ from the views of healthcare professionals and policy makers $\left[^{5}-{ }^{7}\right]$. Also, patients' perspectives on the quality of care have become more prominent in research and policy since the introduction of the concept of patient-centered care in many countries $\left[{ }^{8},{ }^{9}\right]$. This concept aims to empower patients with respect to their healthcare decisions and to (re)structure the healthcare system according to their needs.

Patients' views on quality of care have often been conceptualized as patient satisfaction $\left[{ }^{10}\right.$ ${ }^{12}$ ]. A disadvantage of these surveys is that the scores are extremely subjective, highly skewed ( $>90 \%$ are satisfied), and influenced by personal preference and patient expectation $\left[{ }^{13}\right]$. Caregivers and healthcare services cannot influence patients' expectations, but can 
change the actual experiences. Therefore, a more refined and less subjective instrument for evaluating healthcare quality from the patients' perspective seems necessary. The Consumer Quality index (CQ-index) provides such an instrument $\left[{ }^{14},{ }^{15}\right]$.

The CQ-index is based on two families of surveys that measures patients' experiences. The first family of surveys that is used is the Consumer Assessment of Healthcare Providers and Systems (CAHPS $\left.{ }^{\circledR}\right)$, which is well established and widely used in USA (www.cahps.ahrq.gov). This methodology comprises standardized protocols and manuals concerning sampling, data collection, data entry, data analysis and data reporting, which are also used as reference for CQ-index research. Furthermore, the lay out and answering categories on a four-point scale (never, sometimes, usually, always), three-point scale (not a problem, a small problem, a big problem), global ratings (ranging from 0 to 10 , with a score of 10 indicating the best possible score) and referring to the frequency of experienced events in a certain time period ('In the last 12 months, how often...') were taken from the CAHPS. The second family of instruments that is used is QUOTE (QUality Of care Through the patient's Eyes), which has been developed in the Netherlands $\left[{ }^{16-20}\right]$. From this methodology the questions about importance (answering categories 'not important', 'fairly important', 'important' and 'extremely important') were added into the CQ-index methodology. Also, the concept to include disease-specific items of healthcare services is derived from the QUOTE instruments. The combination of these survey features has an outcome that every CQ-index exists as two parts: one about patients' experiences and one about the important patients' award to quality aspects.

Within rapid development of CQ-index instruments (up to 25), priority has been given to the development of a new instrument for patients with RA. The CQ-index RA is a diseasespecific survey, designed to assess patients' experiences and importance on quality aspects. Patients with RA are 'heavy healthcare users', most of them use two types of healthcare services besides the rheumatologist $\left[{ }^{4}\right]$. For patients to decide which specific provider to choose, consumer information about the quality of care of these providers can be helpful. Measuring patient experiences enables us to provide such information. In addition, the CQindex allows professionals to compare the quality of care they provide with colleagues in the same profession. This instrument may also be an important tool for healthcare providers to monitor their quality of care. Finally, the CQ-index information identifies elements of care that, according to patients, are particularly eligible for improvement.

The aim of this article is to provide an instrument to measure patients' experiences about the healthcare. For this purpose, information on the content and psychometric characteristics of the developed CQ-index RA, as well as on the importance patients assign to the different quality aspects are presented.

\section{PATIENTS AND METHODS}

\section{The creation of the CQ-index rheumatoid arthritis questionnaire}

The survey was formed following the protocols of the CQ-index standard, which is based on the CAHPS and the QUOTE $\left[{ }^{15},{ }^{21}\right]$. A draft questionnaire was constructed using input from two focus group discussions with in total 22 patients with RA, existing questionnaires measuring patients' experiences with quality of rheumatic care (i.e. QUOTE-Rheumatic patients $\left[{ }^{20}\right]$ ) and professional guidelines for RA [developed by the Dutch Institute for Healthcare Improvement (CBO)]. The draft questionnaire was presented to an expert panel (health insurance companies, a patient organization, healthcare providers, patients with rheumatoid arthritis) to assemble comments and improve the instrument. Their comments were included in the second draft of the questionnaire, which was used, after cognitive testing, to test its psychometric properties. 


\section{CQ-index RA experience}

The pilot instrument consisted of two parts, the CQ-index RA experience and the CQ-index RA importance. The first part, the CQ-index RA experience, contained 15 items on person characteristics (e.g. age, education, patient's self-reported physical and psychological health), 6 global ratings (of caregiver during control of care, professional who gives medication, specialized nurse, therapist, medical specialist who performs the surgical procedure, rheumatic care in general), and 114 experienced items regarding the actual experiences of patients with specific quality aspects of care. Other items were instruction items or items with answering categories other than the standard format. The items were divided in 16 themes (Table 1 ).

[table 1]

The answering formats of the experience items were: (1) never, sometimes, usually, and always, (2) not a problem, a small problem, and a big problem, and (3) yes and no. The global ratings ranged from 0 to 10, with a score of 10 indicating the best possible score. If questions were not applicable, an answering option was added. The grade of education was divided into 'no education and secondary education' and 'higher than secondary education'. The self-reported physical and psychological health was assessed using a five-point scale: 'excellent', 'very good', 'good', 'fair' and 'poor'. The instrument instructed respondents to reflect on their experiences in the last 12 months.

In the second part, the CQ-index RA importance, 69 importance items were included, which were designed to assess the importance that patients attribute to aspects of healthcare, using a four-point scale: 'not important', 'fairly important', 'important' and 'extremely important'. The importance survey contained fewer items because quality aspects such as 'to be taken seriously' applied to healthcare professionals in general rather than each healthcare professional of a particular discipline.

\section{Subjects}

A total of 590 patients with RA were selected from the files of four health insurance companies. Inclusion criteria were: (1) being older than 18 years of age, (2) having received rheumatic care in the last 12 months (based on declared costs) and (3) not being approached in the past for other CQ-index surveys. Selecting patients from the files of health insurance companies provided us with a random selection of the RA population, which was heterogeneous in treatments they received.

\section{Data collection}

This study was conducted in the Netherlands in the summer of 2007. All selected patients received a mail from their health insurance company with the request to fill out the CQ-index RA experience and CQ-index RA importance. A "thank you" card was sent to all patients 1 week later. Non-respondents received a second survey and letter in the fifth week, and a reminder letter in the seventh week. The mailing packs with the questionnaires included a stamped addressed envelope $\left[{ }^{22}\right]$.

\section{Analyses}

\section{Response}

The response rate was calculated after excluding the patients who were not willing or able to participate, replied double, or responded negatively to the question whether they had received rheumatic care in the last 12 months. Furthermore, patients who stated that they did not answer the questions themselves and who filled out less then half of the core items (items that should be answered by all respondents) were also excluded $\left[{ }^{21},{ }^{23}\right]$.

\section{Subjects}


To determine whether the respondents and non-respondents differ they were compared on age ( $t$ test) and $\operatorname{sex}(\chi 2$ test).

\section{Dimension structure}

Conducting one explorative factor analysis with a direct oblimin rotation was not possible, because not all items applied to all patients. Therefore, several explorative factor analyses (EFA) with a direct oblimin rotation were conducted on groups of different items (themes) of the experience survey to examine the structure of the questionnaire and the relationship between items with similar answering categories. The factor analyses were accurate if the Kaiser-Meyer-Olkin Measure of Sampling Adequacy (KMO) was higher than 0.60. The number of factors per factor analyze was determined by Kaiser's criterion (Eigenvalues $>1.00$ ). If the factor loading of an item exceeded the criterion of 0.40 , the item was assigned to that particular factor. If an item loaded across multiple factors, it was assigned to the factor where it had the highest loading.

\section{Reliability}

The internal consistency reliability of the scales from the experience data was estimated using Cronbach's alpha, where an alpha value of 0.70 or more was considered satisfactory $\left[{ }^{24}\right]$. Item-total correlations (ITC) were also calculated, to correct for item overlap and check for homogeneity of the simple-summated scales, which were created from items that loaded strongly on the factors(criterion $>0.4$ ITC) $\left[{ }^{25}\right]$. For one module (first visit rheumatologist), the reliability of a scale was calculated by the Kuder-Richardson Formula 20 (KR-20), which is the alternative method to assess the reliability for dichotomous items (yes/no) $\left.{ }^{26}\right]$.

\section{Importance}

The importance scores were calculated to determine the mean importance of each quality aspect $($ not important $=1$, important $=2$, fairly important $=3$, extremely important $=4$ ).

\section{Quality improvement score}

This score represents the proportion of respondents who have had a negative experience ('never/sometimes', 'no' or 'a big problem') on a quality aspect multiplied by the importance score of the same quality aspect (range 1 'not important' to 4 'extremely important'). The quality improvement score is a score that gives healthcare providers information about which quality aspects are particularly eligible for improvement; the higher the score, the more potential there is for improvement.

Analyses were performed using SPSS $14.0^{\circledR}$.

\section{RESULTS}

\section{Response}

At the end of the data collection period, 472 patients returned the CQ-index RA experience and 445 patients returned the CQ-index RA importance. After exclusion, the experience data of 407 patients $(69 \%)$ and the importance data of 385 patients $(65 \%)$ were analyzed.

\section{Subjects}

The majority of the respondents were female (72.7\%), and had an education on a secondary or lower level $(50 \%)$. The self-reported physical health was moderate $(47 \%)$ or good $(41 \%)$, and the self-reported psychological health was mostly good (61\%) followed by very good $(12 \%)$ and excellent $(12 \%)$. Respondents and non-respondents differed from each other concerning age (mean age was 62.9 vs. 59.7 years; $t=2.86 ; p=0.004$ ), but not concerning gender $\left(\chi^{2}=1.76, p=0.18\right)$. 
Zuidgeest, M., Sixma, H., Rademakers, J. Measuring patients' experiences with rheumatic caren the consumer quality index rheumatoid arthritis. Rheumatology International: 2009

\section{Dimensional structure experience survey}

Eight EFA were performed for different themes of the CQ-index RA Experience survey (themes 4-10, 13; see Table 1). For one explorative factor analysis (theme 13 'Financial compensation') the $\mathrm{KMO}$ value was not sufficient $(\mathrm{KMO}=0.50)$. The primary factor loadings based on the pattern matrix are presented in Table 2. In total, eleven factors were formed: (1) Conduct caregiver during control of care, (2) Competence caregiver during control of care, (3) Remaining items control of care, (4) Competence caregiver medication, (5) Conduct specialized nurse, (6) Competence specialized nurse, (7) Conduct therapist, (8) Remaining items therapist, (9) Conduct psychological care, (10) Conduct occupational physician, (11) Cooperation, and (12) Remaining items cooperation. With the exception of question 35 (Q35, factor 1, $\alpha=0.38$ ), all items used in the scales exhibited factor loadings exceeding 0.40. Q35 was removed from factor 1. All items that did not fit in a scale were reported separately (not presented in this article).

\section{[TABLE 2]}

\section{Reliability}

The fourth column $(\alpha 1)$ of Table 2 shows the Cronbach's alpha coefficients for the 11 formed factors, which ranged from 0.00 to 0.94 . Three factors had poor reliability resulting in Cronbach's alpha coefficients of 0.00, 0.37 and 0.39. Removal of any of the items did not increase the alpha coefficient to the threshold of 0.70 (see column 5 of Table 2), and therefore, we were not able to create reliable scales with these items. One factor displayed a relatively low reliability (factor 6; $\alpha=0.67$ ), after removing Q50 from this factor, Cronbach's alpha increased to 0.86 . The internal consistency was tested for a thirteenth factor consisting of seven dichotomous items. In this factor Q17 had a low ITC, which showed that this question does not fit well in this factor. Excluding this item resulted in a KR-20 coefficient of 0.86 , indicating a good reliability for factor 13 'conduct rheumatologist'. Regarding the other formed scales (except for the scales with a poor reliability), the ITC was adequate. In total, ten reliable scales ranging from 0.77 to 0.94 were constructed (factors 1-2, 4-7, 9-11, 13; see Table 2).

\section{Importance scores}

Table 3 presents the ten most important quality aspects mentioned by the respondents. Patients rate the item 'caregivers consider other medication when prescribing drugs' as the most important quality aspect (importance score $=3.7$ ). Information about the risks and the long-term consequences of a surgical procedure, the process of the surgical procedure and the rules for what (not) to do after a surgical procedure are important (3.5-3.6). The rapid accessibility and availability of care (3.5-3.6) are also valued highly. Finally, caregivers have to take patients seriously (3.5) and patients need to discuss arrangements about what to do when RA deteriorates (3.5). Items that did not fit a scale were candidates to be removed from the questionnaire (reliability analysis). Other arguments for adjusting this instrument were based on the dimensional structure, importance scores, and comments of expert panel. For more details see rapport of Zuidgeest et al. $\left[{ }^{27}\right]$.

\section{[TABLE 3]}

\section{[TABLE 4]}

\section{DISCUSSION}

The aim of this study was to illustrate that patients' experiences can be reliably measured with the CQ-index and therefore data collected with this instrument can be an important source to evaluate quality of care. The content, the psychometric characteristics of the CQ- 
index instrument for patients with RA, and patients' views on the quality of rheumatic care were investigated. Our findings show that the multidisciplinary provides us information regarding experiences of patients with RA with several healthcare professionals (rheumatologist, specialized nurse, therapist, occupational physician, medical specialist, psychological caregiver). The final version of the questionnaire consists of ten scales with good reliability ranging from 0.77 to 0.94 . Analysis revealed that the utmost important issue according to patients' was alertness when prescribing drugs. Providing information on a special website of the hospital about RA was the quality aspect that needs the most consideration, as appeared from the quality improvement score.

Measuring patient's experiences to evaluate quality of care is relatively new and goes beyond measuring patient satisfaction, which is a multidimensional concept, influenced by personal preferences and patient expectations. By separating the dimensions 'experience' and 'importance' individual providers and healthcare organizations get a clearer view on the quality aspects that are susceptible for improvement; where the actual care does not meet the needs and expectations of patients. Patients' experiences are useful as an extra source for quality assessment, next to clinical indicators and methods.

The fact that this new instrument represents a multidisciplinary survey is rather a unique feature, as most research predominantly focuses on a particular discipline, e.g. rheumatology $\left[{ }^{28}\right]$. Jacobi et al. $\left.{ }^{29}\right]$ was the first who discussed research of multidisciplinary healthcare utilization among patients with RA with different caregivers (general practitioner, medical specialists, allied healthcare, home care). They reported inadequate quality in the field of rheumatic expertise, particularly for general practitioners, physiotherapists, home nurses and home help, and in the field of information on medication and treatment for rheumatologists and general practitioners. We were able to partly replicate this finding in our study. We also found inadequate quality on the aspect 'giving information about home adjustments' and on aspects regarding information topics. In our study, home nurses and home help were not evaluated.

Our finding that alertness when prescribing drugs is the utmost important aspect according to patients is not very surprising, considering the average daily intake of two doses of drugs $\left[{ }^{30}\right]$. The ten displayed quality aspects differed little (importance score between 3.49 and 3.65), which showed that patients with RA regard these quality aspects in general as 'important' to 'extremely important'. The aspect with the highest possibility for improvement was providing of information on a special website of the hospital. A study of Culver and Chadwick $\left.{ }^{31}\right]$ revealed that the Internet is a poor source of English information for patients with RA. Quality information was scarce and finding information was timeconsuming. Hospitals may anticipate on this by providing their own information about RA as service to their patients.

Though the CQ-index RA was a relatively long questionnaire, the response rate was $69 \%$. This is consistent with other disease-specific surveys $\left[{ }^{16}\right]$. The fact that three reminders were sent may have contributed to the relatively high response $\left[{ }^{32}\right]$. It is known that elderly women are more likely to return the questionnaire than young men $\left[{ }^{14}\right]$. In our study, we also found that older patients returned the questionnaire more often than younger patients, there was, however, no difference between male and female respondents. This could have had an effect on the results, because older people generally report more positive experiences than younger people $\left[{ }^{33},{ }^{34}\right]$. In other words, the experiences of patients could be biased in a positive direction.

CQ-index instruments are based on a multiphase development process, starting with focus group discussions and ending with large quantitative testing. In this large quantitative testing, relevant case mix adjusters are selected and used in the instruments developed so far $\left[{ }^{35}\right]$. Also other CQ-index instruments have revealed good ability to measure differences between healthcare providers, so called discriminative power $\left[{ }^{36},{ }^{37}\right]$. Information derived from CQ-index instruments was successfully translated in public choice information on a special website (www.kiesbeter.nl). 
Zuidgeest, M., Sixma, H., Rademakers, J. Measuring patients' experiences with rheumatic care: the consumer quality index rheumatoid arthritis. Rheumatology International: 2009

Because the CQ-index method is standardized in measuring consumer experiences, a big advantage is that quality information can be compared between different settings and/or different healthcare sectors. This contributes to the increasing transparency and performance providing of different healthcare providers. Providers can look to each others performance and adopt, where necessary, initiatives that have been used successfully in the past. In conclusion, it is possible to reliably measure patients' experiences with the quality of rheumatic care. The CQ-index RA is able to identify those aspects of care that require extra consideration. In addition, the instrument can be used in further surveillance tools in evaluating performance of different healthcare providers. Therefore, in a next phase, the CQindex RA will be adjusted and tested on its ability to discriminate between healthcare providers on the constructed scales and quality aspects.

Acknowledgments

This study was supported by the Netherlands Organization for Health Research and Development (ZonMw) and Stichting Miletus (a concordance of Dutch health insurance companies). The authors would like to acknowledge the contribution of the expert panel that participated in our study: A. Hartveld (Rheumatism Patients League), C. van Weert, Msc. (Stichting Miletus, director), C. de Vries, MD (insurance company VGZ [UVIT]), G. A. Bouman, Msc. (Stichting Miletus), Gertjan Vos, H. Bruins-Slot, MD, PhD (health insurance company Delta Lloyd, J. J. van Croonenborg, Msc. (the Dutch Institute for Healthcare Improvement, CBO), I. J. M. Harms, MD (health insurance company Menzis, M. ScholteVoshaar (Rheumatism Patients League), M. H. Hemrika, MD. (insurance company Agis, P. Kortenhoeven (Rheumatism Patients League, chair expert panel), R. Huisman-Hatzmann (hospital Diakonessenhuis Utrecht, specialized nurse) and T. L. Jansen, MD, PhD (Commissioner Quality, Netherlands Associate for Rheumatology, rheumatologist).

\section{REFERENCES}

Avis M, Bond M, Arthur A (1995) Satisfying solutions? A review of some unresolved issues in the measurement of patient satisfaction. J Adv Nurs 22(2):316-322. doi:10.1046/j.13652648.1995.22020316.x

Groenewegen PP, Kerssens JJ, Sixma HJ, van der Eijk I, Boerma WG (2005) What is important in evaluating health care quality? An international comparison of user views. BMC Health Serv Res 5(1):16. doi:10.1186/1472-6963-5-16

Richards T (1999) Patients' priorities. BMJ 318(7179):277

Jacobi CE, Triemstra M, Rupp I, Dinant HJ, van den Bos GA (2001) Health care utilization among rheumatoid arthritis patients referred to a rheumatology center: unequal needs, unequal care? Arthritis Rheum 45(4):324-330. doi:10.1002/1529-131(200108)45:4<324: :AID-ART344>3.0.CO;2-1

Batalden P (1987) Quality in medicine-the view from the Hospital Corporation of America. An interview with Paul Batalden, M.D., HCA vice president for medical care (by Richard L. Reece). Minn Med 70(12):678, 682-678, 684

Bensing J (1991) Doctor-patient communication and the quality of care. Soc Sci Med 32(11):1301-1310. doi:10.1016/0277-9536(91)90047-G

Potts M, Weinberger M, Brandt KD (1984) Views of patients and providers regarding the importance of various aspects of an arthritis treatment program. J Rheumatol 11(1):71-75

Gabel JR, Lo Sasso AT, Rice T (2002) Consumer-driven health plans: are they more than talk now? Health Aff (Millwood). Suppl Web Exclusives:W395-W407

Herzlinger RE, Parsa-Parsi R (2004) Consumer-driven health care: lessons from Switzerland. JAMA 292(10):1213-1220. doi:10.1001/jama.292.10.1213

Kirsner RS, Federman DG (1997) Patient satisfaction. Quality of care from the patients' perspective. Arch Dermatol 133(11):1427-1431. doi:10.1001/archderm.133.11.1427

Sitzia J, Wood N (1997) Patient satisfaction: a review of issues and concepts. Soc Sci Med 45(12):1829-1843. doi:10.1016/S0277-9536(97)00128-7 
Zuidgeest, M., Sixma, H., Rademakers, J. Measuring patients' experiences with rheumatic care: the consumer quality index rheumatoid arthritis. Rheumatology International: 2009

van Campen C, Sixma H, Friele RD, Kerssens JJ, Peters L (1995) Quality of care and patient satisfaction: a review of measuring instruments. Med Care Res Rev 52(1):109-133. doi:10.1177/107755879505200107

Yang $\mathrm{H}$, Thoms S (2000) Patient's experience and satisfaction survey on general practice: international development and Australian experience. J Chinese Pract 9(11):879-880

Delnoij D, Ten Asbroek G, Arah O, De Koning J, Stam P, Poll A et al (2004) Made in the USA: the import of American Consumer Assessment of Health Plan Surveys (CAHPS) into the Dutch social insurance system. Eur J Public Health 14:43. doi:10.1093/eurpub/14.1.43

Sixma H, Triemstra M, Delnoij D (2007) The consumer quality index (CQI): background, general characteristics and advantages of a standardized approach to measure user views on quality of care. Eur J Public Health 17(Suppl 2):33-34. doi:10.1093/eurpub/ckm061

Nijkamp MD, Sixma HJ, Afman H, Hiddema F, Koopmans SA, van den BB et al (2002) Quality of care from the perspective of the cataract patient. QUOTE cataract questionnaire. J Cataract Refract Surg 28(11):1924-1931. doi:10.1016/S0886-3350(02)01373-1

Sixma H, Kerssens J, Van Campen C, Peters L (1998) Quality of care from the patients' perspective: from theoretical concept to a new measuring instrument. Health Expect 1:8295. doi:10.1046/j.1369-6513.1998.00004.x

Sixma HJ, van Campen C, Kerssens JJ, Peters L (2000) Quality of care from the perspective of elderly people: the QUOTE-elderly instrument. Age Ageing 29(2):173-178. doi:10.1093/ageing/29.2.173

van der Eijk I, Sixma H, Smeets T, Veloso FT, Odes S, Montague S et al (2001) Quality of health care in inflammatory bowel disease: development of a reliable questionnaire (QUOTE-IBD) and first results. Am J Gastroenterol 96(12):3329-3336. doi:10.1016/S00029270(01)03896-5

van Campen C, Sixma HJ, Kerssens JJ, Peters L, Rasker JJ (1998) Assessing patients' priorities and perceptions of the quality of health care: the development of the QUOTERheumatic-Patients instrument. Br J Rheumatol 37(4):362-368.

doi:10.1093/rheumatology/37.4.362

Sixma H, Delnoij DM, Stubbe JH, Triemstra M, Damman O, Vriens B, et al (2007) Handboek CQI Meetinstrumenten. Een handleiding voor de ontwikkeling en het gebruik van Consumer Quality Index (CQI) vragenlijsten (Manual CQI instruments. A instruction for the development and use of Consumer Quality Index (CQI) questionnaires). Centrum Klantervaring Zorg, Utrecht

Dillman DA (2000) Mail and internet surveys the tailored Design Method. Wiley, New York CAHPS $^{\circledR}$ Survey Users' Network (2002) Preparing the data for analysis. Westat, Rockville Cronbach LJ (1951) Coefficient alpha and the internal structure of tests. Psychometrika 16:297-334. doi:10.1007/BF02310555

Streiner DL, Norman GR (2003) Health measurement scales: a practical guide to their development and use, 3rd edn. Oxford University Press, Oxford

Kuder GF, Richardson MW (1937) The theory of the estimation of test reliability. Psychometrika 2:151-160. doi:10.1007/BF02288391

Zuidgeest M, Hendriks M, Triemstra AHM, Sixma HJ (2007) CQ-index Reumatoide Artritis: meetinstrumentontwikkeling: kwaliteit van reumazorg vanuit het perspectief van patienten met reumatoide artritis (CQ-index Rheumatoid Arthritis: measurement development. Quality of rheumatic care through the patients' eyes. NIVEL, Utrecht

Ward MM (1997) Rheumatology visit frequency and changes in functional disability and pain in patients with rheumatoid arthritis. J Rheumatol 24(1):35-42

Jacobi CE, Boshuizen HC, Rupp I, Dinant HJ, van den Bos GA (2004) Quality of rheumatoid arthritis care: the patient's perspective. Int J Qual Health Care 16(1):73-81. doi:10.1093/intqhc/mzh009

Blomqvist P, Feltelius N, Ekbom A, Klareskog L (2000) Rheumatoid arthritis in Sweden. Drug prescriptions, costs, and adverse drug reactions. J Rheumatol 27(5):1171-1177

Culver M, Chadwick A (2005) Internet information on rheumatoid arthritis: an evaluation. 
Zuidgeest, M., Sixma, H., Rademakers, J. Measuring patients' experiences with rheumatic care: the consumer quality index rheumatoid arthritis. Rheumatology International: 2009

Musculoskeletal Care 3(1):33-43. doi:10.1002/msc.24

Dillman DA (2000) Mail and internet surveys the tailored Design Method. Wiley, New York O'Malley AJ, Zaslavsky AM, Elliott MN, Zaborski L, Cleary PD (2005) Case-mix adjustment of the CAHPS Hospital Survey. Health Serv Res 40(6 Pt 2):2162-2181.

doi:10.1111/j.1475-6773.2005.00470.x

Zaslavsky AM, Zaborski L, Ding L (2001) Adjusting performance measures to ensure equitable plan comparisons. Health Care Financ Rev 22:109-126

Damman OC, Stubbe JH, Hendriks M, Arah OA, Spreeuwenberg P, Delnoij DM, Groenewegen PP (2009) Using multilevel modeling to assess case-mix adjusters in consumer experience surveys in health care. Med Care 47(4):496-503. doi:10.1097/MLR.0b013e31818afa05

Stubbe JH, Brouwer W, Delnoij DM (2007) Patients' experiences with quality of hospital care: the Consumer Quality Index Cataract Questionnaire. BMC Ophthalmol 7:14. doi:10.1186/1471-2415-7-14

Stubbe JH, Gelsema T, Delnoij DM (2007) The Consumer Quality Index Hip Knee Questionnaire measuring patients' experiences with quality of care after a total hip or knee arthroplasty. BMC Health Serv Res 7:60. doi:10.1186/1472-6963-7-60

\section{TABLES}

Table 1 Content CQ-index RA experience (number of questions)

Introduction (1)

Care by general practitioner (7)

First visit rheumatologist (9)

Control of care (20)

Prescribing medication (5)

Specialized nurse (13)

Therapist (12) about RA

Psychosocial care (12)

Occupational physician (8)

Cooperation and adaptation (9)

Operation (11)

Information and knowledge (11)

Financial compensations (6)

Global rating rheumatic care (1)

General items (15)

Improving questionnaire (2)

Table 2 Factor loadings of the items in the CQ-index experience according to the eight explorative factor analysis with oblimin rotation (EFA1-EFA8)

\begin{tabular}{|l|l||l|l|l|l|}
\hline No. & Item description & $\begin{array}{c}\text { Factor } \\
\text { loading }\end{array}$ & $\boldsymbol{\alpha 1}$ & $\boldsymbol{\alpha 2}$ & ITC \\
\hline \hline EFA 1 & $\begin{array}{l}\text { Factor 1: Conduct caregiver control of care } \\
\text { (rheumatologist or specialized nurse) }\end{array}$ & & 0.86 & & \\
\hline
\end{tabular}




\begin{tabular}{|c|c|c|c|c|c|}
\hline No. & Item description & $\begin{array}{r}\begin{array}{r}\text { Factor } \\
\text { loading }\end{array} \\
\end{array}$ & $\alpha 1$ & $\alpha 2$ & ITC \\
\hline Q20. & Caregiver took me seriously & 0.83 & & 0.85 & 0.66 \\
\hline Q21. & Caregiver spent enough time & 0.82 & & 0.83 & 0.72 \\
\hline Q22. & Caregiver listened carefully & 0.88 & & 0.81 & 0.80 \\
\hline Q23. & Caregiver took interest in you as a person & 0.88 & & 0.80 & 0.77 \\
\hline Q24. & $\begin{array}{l}\text { Caregiver took into account your personal } \\
\text { situation }\end{array}$ & 0.80 & & 0.86 & 0.68 \\
\hline Q35. & Caregiver was always the same person & $0.38^{\mathrm{a}}$ & & - & - \\
\hline EFA 1 & Factor 2: Competence caregiver control of care & & 0.85 & & \\
\hline Q29 & $\begin{array}{l}\text { Caregiver explained research results clearly } \\
\end{array}$ & 0.42 & & 0.82 & 0.63 \\
\hline Q30. & $\begin{array}{l}\text { Discussed whether the current treatment was } \\
\text { best for you }\end{array}$ & 0.68 & & 0.81 & 0.71 \\
\hline Q31. & $\begin{array}{l}\text { Decisions about treatment were shared between } \\
\text { you and caregiver }\end{array}$ & 0.73 & & 0.81 & 0.71 \\
\hline Q32. & $\begin{array}{l}\text { Caregiver took into account your wishes about } \\
\text { treatment }\end{array}$ & 0.61 & & 0.80 & 0.76 \\
\hline Q33. & $\begin{array}{l}\text { Rapid access to rheumatologist if complaints } \\
\text { got worse }\end{array}$ & 0.86 & & $0.86^{\mathrm{b}}$ & 0.41 \\
\hline Q34. & Opportunity to ask questions & 0.74 & & 0.83 & 0.60 \\
\hline EFA 1 & Factor 3: Remaining items control of care & & 0.00 & & \\
\hline Q25. & Seen within 15 min of your appointment & -0.60 & & n.c. & $c^{-0.00}$ \\
\hline Q36. & $\begin{array}{l}\text { Caregiver referred you to other caregivers if } \\
\text { you wanted }\end{array}$ & 0.69 & & n.c. & -0.00 \\
\hline EFA 2 & Factor 4: Competence medication giver & & 0.77 & & \\
\hline Q39. & Caregiver was aware of your personal situation & 0.81 & & 0.72 & 0.57 \\
\hline Q40. & $\begin{array}{l}\text { Caregiver considered other medication when } \\
\text { prescribing drugs }\end{array}$ & 0.86 & & 0.64 & 0.65 \\
\hline Q41. & $\begin{array}{l}\text { Receiving adequate assistance with } \\
\text { administering drugs }\end{array}$ & 0.82 & & 0.70 & 0.59 \\
\hline EFA 3 & Factor 5: Conduct specialized nurse & & 0.89 & & \\
\hline Q44. & Specialized nurse took you seriously & 0.82 & & 0.86 & 0.76 \\
\hline Q45. & Specialized nurse spent enough time & 0.87 & & 0.85 & 0.82 \\
\hline Q46. & Specialized nurse listened carefully & 0.79 & & 0.85 & 0.80 \\
\hline Q47. & Specialized nurse showed personal interest & 0.86 & & 0.89 & 0.64 \\
\hline Q48. & Specialized nurse explained information clearly & 0.79 & & 0.87 & 0.65 \\
\hline Q49. & Opportunity to ask questions & 0.70 & & 0.87 & 0.67 \\
\hline EFA 3 & Factor 6: Competence specialized nurse & & 0.77 & & \\
\hline Q50. & $\begin{array}{l}\text { Specialized nurse referred you to other } \\
\text { caregivers if you wanted }\end{array}$ & 0.70 & & 0.86 & 0.30 \\
\hline Q51. & $\begin{array}{l}\text { Specialized nurse gave advice, instructions } \\
\text { and/or education about RA }\end{array}$ & 0.78 & & 0.41 & 0.66 \\
\hline
\end{tabular}




\begin{tabular}{|c|c|c|c|c|c|}
\hline No. & Item description & $\begin{array}{r}\begin{array}{r}\text { Factor } \\
\text { loading }\end{array} \\
\text { oading }\end{array}$ & $\alpha 1$ & $\alpha 2$ & ITC \\
\hline Q52. & $\begin{array}{l}\text { Specialized nurse advised you to function as } \\
\text { normal as possible }\end{array}$ & 0.76 & & 0.45 & 0.58 \\
\hline EFA 4 & Factor 7: Conduct therapist & & 0.81 & & \\
\hline Q60. & Therapist spent enough time & 0.71 & & 0.76 & 0.65 \\
\hline Q61. & Therapist listened carefully & 0.80 & & 0.74 & 0.74 \\
\hline Q62. & Therapist had personal attention for you & 0.77 & & 0.77 & 0.63 \\
\hline Q63. & $\begin{array}{l}\text { Therapist clarified the importance of } \\
\text { compliance to his treatment }\end{array}$ & 0.69 & & 0.80 & 0.53 \\
\hline Q66 & Opportunity to ask questions & 0.64 & & 0.80 & 0.51 \\
\hline $\begin{array}{l}\text { EFA } 4 \\
\end{array}$ & Factor 8: Remaining items therapist & & 0.37 & & \\
\hline Q59. & Therapist took you seriously & $\begin{array}{l}-0.62 \\
\end{array}$ & & 0.53 & 0.01 \\
\hline Q64. & Treatment improved daily activities & 0.55 & & -0.03 & 0.37 \\
\hline Q65. & $\begin{array}{l}\text { Therapist informed you about possible } \\
\text { adjustments }\end{array}$ & 0.50 & & 0.07 & 0.31 \\
\hline EFA 5 & Factor 9: Conduct psychosocial caregiver & & 0.94 & & \\
\hline Q72. & Psychosocial caregiver took you seriously & 0.82 & & 0.94 & 0.75 \\
\hline Q73. & Psychosocial caregiver spent enough time & 0.96 & & 0.93 & 0.93 \\
\hline Q74. & Psychosocial caregiver listened carefully & 0.94 & & 0.93 & 0.89 \\
\hline Q75. & $\begin{array}{l}\text { Psychosocial caregiver showed personal } \\
\text { attention }\end{array}$ & 0.96 & & 0.93 & 0.92 \\
\hline Q76. & $\begin{array}{l}\text { Psychosocial caregiver enquired possible } \\
\text { emotional problems }\end{array}$ & 0.96 & & 0.93 & 0.94 \\
\hline Q77. & $\begin{array}{l}\text { Psychosocial caregiver enquired your partner } \\
\text { or/and children }\end{array}$ & 0.90 & & 0.93 & 0.85 \\
\hline Q78. & $\begin{array}{l}\text { Psychosocial caregiver advised you, despite the } \\
\text { rheumatoid arthritis, to function as good as } \\
\text { possible }\end{array}$ & 0.56 & & 0.97 & 0.50 \\
\hline Q79. & Opportunity to ask questions & 0.91 & & 0.93 & 0.88 \\
\hline EFA 6 & Factor 10: Conduct occupational physician & & 0.89 & & \\
\hline Q82. & Occupational physician took you seriously & 0.82 & & 0.88 & 0.73 \\
\hline Q83. & Occupational physician spent enough time & 0.90 & & 0.87 & 0.81 \\
\hline Q84. & Occupational physician listened carefully & 0.87 & & 0.87 & 0.77 \\
\hline Q85. & Occupational physician had personal attention & 0.93 & & 0.85 & 0.88 \\
\hline Q86. & $\begin{array}{l}\text { Occupational physician advised you to function } \\
\text { as normal as possible }\end{array}$ & 0.75 & & 0.89 & 0.67 \\
\hline Q87. & Opportunity to ask questions & 0.68 & & 0.90 & 0.58 \\
\hline EFA 7 & Factor 11: Cooperation & & 0.89 & & \\
\hline Q88. & Parallel treatments were adjusted to one another & 0.85 & & 0.86 & 0.77 \\
\hline Q89. & Various advises were integrated & 0.89 & & 0.85 & 0.81 \\
\hline Q90. & Caregivers kept their appointments & 0.88 & & 0.85 & 0.83 \\
\hline
\end{tabular}




\begin{tabular}{|l||l|l|l|l|l|}
\hline No. & Item description & $\begin{array}{c}\text { Factor } \\
\text { loading }\end{array}$ & $\boldsymbol{\alpha} 1$ & $\boldsymbol{\alpha 2}$ & ITC \\
\hline \hline Q92 & $\begin{array}{l}\text { Caregivers were aware of other activities of } \\
\text { caregivers }\end{array}$ & 0.78 & & 0.89 & 0.67 \\
\hline \hline Q94. & $\begin{array}{l}\text { After leaving a message, you were phoned } \\
\text { within one workday }\end{array}$ & 0.76 & & 0.89 & 0.63 \\
\hline \hline EFA 8 & Factor 12: Remaining items cooperation & & 0.39 & & \\
\hline \hline Q91. & Caregivers gave conflicting information & 0.77 & & - & 0.26 \\
\hline \hline Q93. & $\begin{array}{l}\text { Telling the same story more than once to } \\
\text { different caregivers }\end{array}$ & 0.82 & & - & 0.26 \\
\hline- & Factor 13: Conduct rheumatologist & & 0.87 & & \\
\hline \hline Q10. & Rheumatologist took you seriously & - & & 0.74 & 0.59 \\
\hline \hline Q11. & Rheumatologist spent enough time & - & & 0.70 & 0.80 \\
\hline \hline Q12. & Rheumatologist listened carefully & - & & 0.70 & 0.80 \\
\hline \hline Q13. & Rheumatologist showed personal attention & - & & 0.72 & 0.58 \\
\hline \hline Q15. & Rheumatologist explained things clearly & - & & 0.74 & 0.51 \\
\hline \hline Q16. & Opportunity to ask questions & - & & 0.74 & 0.61 \\
\hline \hline Q17. & Rheumatologist referred to a specialized nurse & - & & 0.86 & 0.23 \\
\hline
\end{tabular}

Factor loading, Cronbach's alpha whole scale $(\alpha 1)$, Cronbach's alpha of scale if item deleted ( $\alpha 2)$, and the item-total correlation correcting for overlap (ITC) are displayed

With two items in one scale, Cronbach's alpha of scale if item is deleted $(\alpha 2)$ cannot be calculated

n.c. not calculated

${ }^{a}$ Bold typeface factor loading: item does not meet factor loading criterion of 0.4

${ }^{b}$ Bold typeface a2: Chronbach's alpha improves when item is deleted

${ }^{c}$ Bold typeface ITC: item does not meet item-total correlation criterion of 0.4

${ }^{\mathrm{d}} \mathrm{KR}-20$ in stead of $\alpha$

Table 3 The ten highest importance scores

\begin{tabular}{|c|c|c|}
\hline Question & $\begin{array}{l}\text { To what extent would you consider the following } \\
\text { important: }\end{array}$ & $\begin{array}{l}\text { Importance } \\
\text { score }\end{array}$ \\
\hline Q40. & $\begin{array}{l}\text {...caregivers consider your other medication when } \\
\text { prescribing drugs }\end{array}$ & 3.65 \\
\hline Q100. & ...the specialist explains the risks of a surgical procedure & 3.62 \\
\hline Q7. & $\begin{array}{l}\text {...you have a rapid accessibility to a rheumatologist after } \\
\text { referral }\end{array}$ & 3.60 \\
\hline Q6. & $\begin{array}{l}\text {...the general practitioner quickly provides referral to } \\
\text { rheumatologist }\end{array}$ & 3.59 \\
\hline Q102. & $\begin{array}{l}\text {...you are being informed about long-term consequences of a } \\
\text { surgical procedure }\end{array}$ & 3.58 \\
\hline Q33. & $\begin{array}{l}\text {...you are being rapidly sent to the rheumatologist if your } \\
\text { complaints get worse }\end{array}$ & 3.57 \\
\hline Q101. & ...a specialist explains the surgical procedure & 3.56 \\
\hline
\end{tabular}




\begin{tabular}{|c|c|c|}
\hline Question & $\begin{array}{l}\text { To what extent would you consider the following } \\
\text { important: }\end{array}$ & $\begin{array}{l}\text { Importance } \\
\text { score }\end{array}$ \\
\hline Q3. & ...caregivers take you seriously & 3.51 \\
\hline Q103. & $\begin{array}{l}\text {...the specialist provides rules for what (not) to do after a } \\
\text { surgical procedure }\end{array}$ & 3.50 \\
\hline Q96. & $\begin{array}{l}\text {...discuss arrangements regarding what to do when RA } \\
\text { deteriorates, like in an acute attack }\end{array}$ & 3.49 \\
\hline
\end{tabular}

Quality improvement score

In Table 4, ten quality aspects with improvement scores are presented. A score of 2.11 is the highest quality improvement score for the quality aspect 'information on a website of the hospital about RA'. 'Information about reimbursements and contributions about support and devices' $(Q=1.69)$ and 'general practitioner asked about having rigid joints' $(Q=1.61)$ were second and third in this overview. Other aspects concerned 'reporting of a mistake' $(Q=1.59)$, 'more information about adjustments at home' $(Q=1.51)$, 'support concerning domestic activities' $(Q=1.44)$ and 'personal care' $(Q=1.35)$, and 'talking with caregivers if something went wrong' $(Q=1.34)$.

Table 4 Top ten quality improvement scores $(Q)$ with corresponding importance scores $(I)$ and experience score, as proportion negative experience $(E)$ are displayed

\begin{tabular}{|l|l|l|l|l|}
\hline No. & Quality aspect & $\mathrm{I}$ & $\mathrm{E}$ & $\mathrm{Q}$ \\
\hline Q110 & $\begin{array}{l}\text { Providing information of a special website of the hospital about } \\
\text { RA }\end{array}$ & 2.61 & 0.81 & 2.11 \\
\hline Q122 & $\begin{array}{l}\text { Information about reimbursements and contribution about } \\
\text { support and devices }\end{array}$ & 3.31 & 0.51 & 1.69 \\
\hline Q5 & General practitioner asked about having rigid joints & 2.98 & 0.54 & 1.61 \\
\hline Q119 & $\begin{array}{l}\text { Information about reimbursements of different supplementary } \\
\text { insurances of different insurance companies }\end{array}$ & 3.32 & 0.48 & 1.60 \\
\hline Q116 & Reporting a mistakes & 3.32 & 0.48 & 1.59 \\
\hline Q65 & Therapist informed you about getting home adjustments & 3.14 & 0.48 & 1.51 \\
\hline Q96 & $\begin{array}{l}\text { Discussed arrangements regarding what to so when RA } \\
\text { deteriorates }\end{array}$ & 3.49 & 0.43 & 1.50 \\
\hline Q123 & Domestic support & 3.27 & 0.44 & 1.44 \\
\hline Q124 & Support for your personal care & 3.30 & 0.41 & 1.35 \\
\hline Q117 & Caregivers discussed things that went wrong & 3.34 & 0.40 & 1.34 \\
\hline
\end{tabular}

